\title{
The design and experiment of hydraulic power intelligent instrument
}

\author{
QIAO Wei-liang \\ Marine engineering college, Dalian Maritime \\ University \\ Dalian, China \\ e-mail: qiaoweiliangdmu@126.com \\ ZHANG Jun \\ China Classification Society \\ Guangzhou, China \\ e-mail: zhangjun196578123@tom.com
}

\author{
ZHANG Bin-bin \\ Marine engineering college, Dalian Maritime \\ University \\ Dalian, China \\ e-mail: 965784275 @qq.com \\ WANG Sheng-hai \\ Marine engineering college, Dalian Maritime \\ University \\ Dalian, China \\ e-mail: $752867718 @ q q . c o m$
}

\begin{abstract}
In this paper, a newly hydraulic power intelligent instrument is presented and verified. As the important of hydraulic power intelligent instrument, power sensor, which consists of flow rate sensor and pressure sensor, was developed on the base of MEMS technology. And then, with the help of soft programming and circuit design aimed at signal treatment, the hydraulic power intelligent instrument was made. An experiment using closed power recycle hydraulic system was designed verifies the application of hydraulic power intelligent instruments in the field of hydraulic system failure inspection. The results indicate that the hydraulic power intelligent instrument can identify accurately the working condition of hydraulic system.
\end{abstract}

Keywords-hydraulic; power; instrument; failure; inspection

\section{INTRODUCTION}

The hydraulic system is a synthesized system consisting of mechanical, electric and fluid, and is widely applied in various industry fields. It is difficult to identify the hydraulic system failure due to the characteristic of hydraulic system, such as complex contracture, mechanical-fluid coupling, and nonlinear. The hydraulic power intelligent instrument designed in this paper provides a new way to inspect the working condition of hydraulic system.

\section{THE DESIGN OF HYDRAULIC POWER INTELLIGENT INSTRUMENT}

\section{A. The principle and design of hydraulic power sensor}

In the hydraulic system, hydraulic power equals the product of flow rate and pressure. From this point, the power sensor is a complex consisting of flow rate sensor and pressure sensor, which can output hydraulic power signal after treating the flow rate signal and pressure signal.

As with the flow rate sensor, based on the research findings of ship Mechanical \& Electrical Integration lab. in Dalian Maritime University ${ }^{[1-3]}$, this paper designed a pipe reducer, which can produce a differential pressure signal. This signal, whose strength reflects the size of flow rate, is caught by MEMS chip. In this way, the flow rate signal is obtained. The configuration of reducer can be seen in Fig.1. The pipe reducer is printed by 3D printer(Dimension Elite), adopting a kind of newly ABS material, which has the characteristic of higher strengthen, temperature insensitive and no reaction with hydraulic $\mathrm{oil}^{[3]}$. In this paper, diffused silicon piezoresistive pressure transducer is selected as pressure sensor, which can output a DC current signal between $4 \mathrm{~mA}$ and $20 \mathrm{~mA}$.

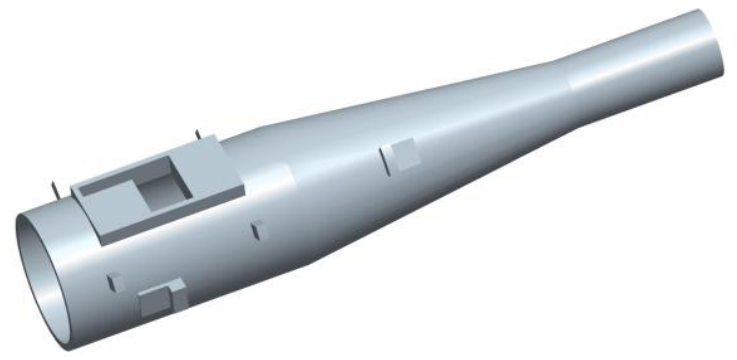

Figure1. the configuration of reducer

The hydraulic power sensor can be obtained after the assembly of flow rate sensor and pressure sensor. It is should be noted that excellent seal is essential for the connection of flow rate sensor. The power sensor is shown in the Fig.2.

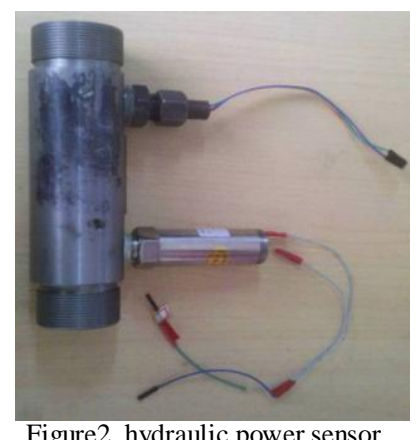

Figure2. hydraulic power sensor 
B. Calibration and performance test of hydraulic power sensor

\section{1) experiment environment}

Experiment platform: DY200011-00 closed hydraulic recycling system, as is shown in Fig.4

Test basis: <GBT 18459-2001 methods for calculating the main static performance specifications of transducers>

Experiment equipment: reducer flow rate sensor designed in this paper; AD693 stabilized electric power; CIG-15 flowmeter; S064C-1flow tester

\section{2) Experiment data}

First, fit the hydraulic power sensor to the testing hydraulic system, and then adjust the frequent of electric motor and the flow rate of hydraulic pump, changing the flow rate from 0 to 45 , then 0 , the step is 5 . the voltage signals acquired by flow rate sensor are recorded in the Tabl.I.

\begin{tabular}{|c|c|c|c|c|c|}
\hline \multirow{2}{*}{$\begin{array}{l}\text { Input } \\
x \\
(\mathrm{~L} / \mathrm{min})\end{array}$} & \multicolumn{5}{|c|}{ output $y \quad(\mathrm{mV})$} \\
\hline & $y_{1}$ & $y_{2}$ & $y_{3}$ & $y_{4}$ & $y_{5}$ \\
\hline 0.0 & 0.3 & 0.2 & 0.3 & 0.2 & 0.3 \\
\hline 5.0 & 1.5 & 1.4 & 1.6 & 1.5 & 1.5 \\
\hline 10.0 & 2.4 & 2.3 & 2.5 & 2.4 & 2.4 \\
\hline 15.0 & 3.3 & 3.1 & 3.4 & 3.3 & 3.4 \\
\hline 20.0 & 4.3 & 4.2 & 4.4 & 4.3 & 4.3 \\
\hline 25.0 & 5.4 & 5.3 & 5.5 & 5.4 & 5.4 \\
\hline 30.0 & 6.5 & 6.3 & 6.5 & 6.5 & 6.4 \\
\hline 35.0 & 7.6 & 7.5 & 7.7 & 7.7 & 7.6 \\
\hline 40.0 & 8.7 & 8.5 & 8.8 & 8.8 & 8.7 \\
\hline 45.0 & 9.8 & 9.6 & 9.9 & 10.0 & 9.8 \\
\hline 45.0 & 9.8 & 9.7 & 9.9 & 10.0 & 9.7 \\
\hline 40.0 & 8.6 & 8.4 & 8.7 & 8.8 & 8.6 \\
\hline 35.0 & 7.4 & 7.4 & 7.5 & 7.6 & 7.4 \\
\hline 30.0 & 6.2 & 6.2 & 6.3 & 6.4 & 6.3 \\
\hline 25.0 & 5.2 & 5.1 & 5.4 & 5.4 & 5.3 \\
\hline 20.0 & 4.1 & 4.0 & 4.3 & 4.2 & 4.2 \\
\hline 15.0 & 3.1 & 3.0 & 3.3 & 3.2 & 3.3 \\
\hline 10.0 & 2.2 & 2.2 & 2.3 & 2.3 & 2.3 \\
\hline 5.0 & 1.4 & 1.4 & 1.5 & 1.5 & 1.5 \\
\hline 0.0 & 0.2 & 0.3 & 0.3 & 0.3 & 0.3 \\
\hline
\end{tabular}

3) Experiment result analysis

The testing data in Tab I. is reasonable after inspection and can be used to analyze the performance of flow rate sensor. In this paper, the performance index of flow rate consists of linearity, hysteresis, combined linearity and hysteresis, repeatability, as well as total uncertainty, which are listed in Tab II.

TABLE II .THE VALUE OF PERFORMANCE INDEX

\begin{tabular}{|l|c|}
\hline \multicolumn{1}{|c|}{ Performance index } & value \\
\hline Linearity & $2.01 \%$ \\
\hline hysteresis & $1.71 \%$ \\
\hline combined linearity and hysteresis & $2.79 \%$ \\
\hline repeatability & $3.37 \%$ \\
\hline total uncertainty & $4.39 \%$ \\
\hline
\end{tabular}

According to the data in Tab II, although the performance of flow rate sensor designed in this paper can not reach the excellent flow rate sensor's, especially the linearity and the total uncertainty, this sensor is not designed for measuring the flow rate accurately, but for the failure inspection of hydraulic system. From this point of view, the sensor designed in this paper meets the anticipation.

\section{The inspection circuit of hydraulic power intelligent instrument $^{[4-7]}$}

The inspection circuit designed in this paper consists of interface module, voltage transformer module, signal acquisition and amplification module, A/D conversion module, power calculation module, as well as wireless receiver and signal display module. The circuit principle diagram is shown in the Fig.3.

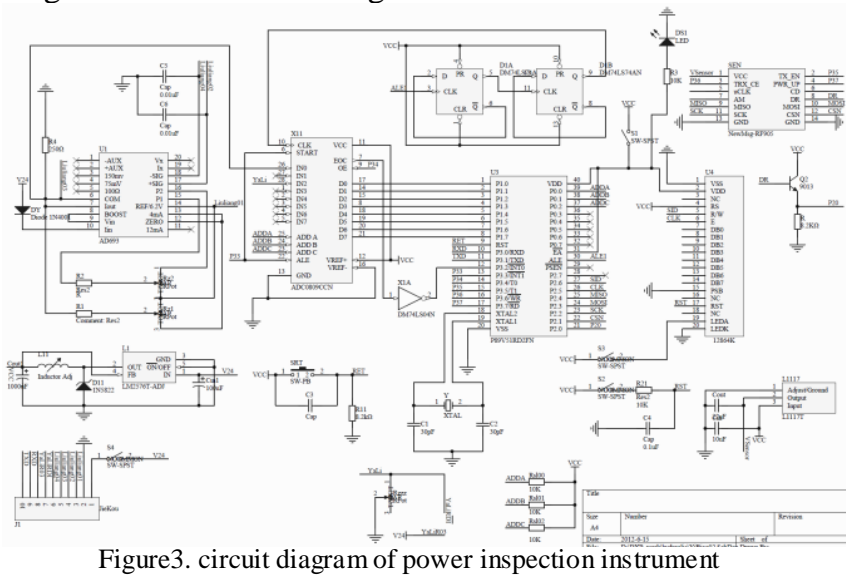

Different module plays different roles: the function of interface module is to connect external electronic power and displayer, and acquire the signal from flow rate sensor and pressure sensor; three different voltages are needed for the power inspection instrument, $24 \mathrm{~V}, 3.3 \mathrm{~V}, 5 \mathrm{~V}$. so the function of voltage transformer is to provide different voltages for the power inspection instrument; The main function of signal acquisition and amplification module is to transfer the voltage signal and current signal acquired by sensor into standard signal; in this paper, New-Msg RF905, which is manufactured by Nordic VLSL, is adopted as wireless module.

\section{Soft programming of hydraulic power intelligent instrument $^{[8]}$}

In this paper, the uVision3 is adapted as soft programming platform using $C$ language. The programme is downloaded to P89V51RD2 by the use of FlashMagic, with the help of the pins of TXD and RXD in MCU and RS232, the soft programming is debugged with CommAssistant. The soft programming in this paper consists of hardware initialized, signal acquisition, power calculation, signal display, wireless receiver and data transmission. As with the general procedure of designing soft programming, after receiving the beginning order, the wireless module acquires the signal of flow rate and pressure, and then calculates the hydraulic power, which is sent to displayer by the wireless module.

\section{WORKING MECHANISM OF HYDRAULIC POWER INTELLIGENT INSTRUMENT}

\section{A. The whole design of failure inspection}

The failure inspection for hydraulic system designed in this paper consists of PC, communication module, data transfer station, inspection instrument and power sensor. The role of above modules is described as follow: the PC is functioned for failure inspection and alarm; communication module transfers data between PC and 
MCU; the data transfer station is aimed at receiving signal from hydraulic system and transferring order from PC; the inspection instrument is responsible for flow rate and pressure signal acquisition, power calculation, display and wireless transmission.

\section{B. Data transmission}

The duty of data transmission is achieved by data transfer station, which consists of MCU and wireless module. At the same time, in the case of more than one power sensor, the data transfer station harmonizes the data transmission of different power sensors, receives the characteristic parameters from different power sensors continuously, transfers the data to $\mathrm{PC}$, and transfers order from PC to different sensors.

\section{The transmission between data transfer station and $P C$}

In the hydraulic failure inspection system, the function of PC is to receive inspection signal, analyze the acquired signal, and output alarm signal. The data communication between data transfer station and PC is achieved by the combination of RS232 and HL-340: RS232 transfers level signal of TTL into COM serial signal; and HL-340 transfers COM serial signal into USB signal.

\section{The soft programming design of $P C$}

The purpose of the PC is to receive and analyze signals, as well as output alarm. In this paper, the soft programming is finished by Visual Basic 6.0.

1) Serial communication: it is achieved by inducing a MSComm to the Frame in Visual Basic.

2) Design data base: the data base consists of dynamic signal acquision sheet and system state parameter sheet and it is designed by SQL Server 2005.

3) graphics user interface of inspection system: it is designed for displaying parameters intuitively.

4) design the multi-instrument failure inspection system: the system is designed for achieving the function of state identification of power intelligent instrument.

\section{FAILURE INSPECTION EXPERIMENT OF HYDRAULIC POWER INTELLIGENT INSTRUMENT}

\section{A. Experiment environment}

Experiment platform: DY200011-00 closed hydraulic recycling system, as is shown in Fig.4

fault simulation: backpressure relief valve opens; main relief valve opens; ball valve closes slightly

location of instrument: as is shown in Fig. 4 $30 \mathrm{~Hz}$

normal condition: the frequent of electric motor is

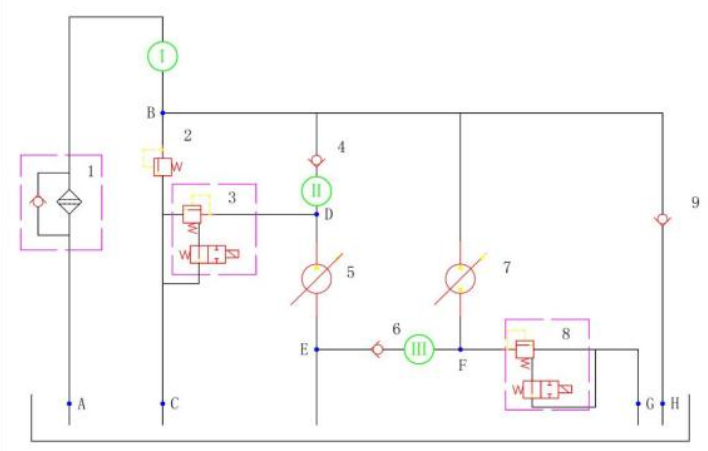

Figure 5. location of inspection instruments

(note: I, II and III shown in figure are the locations of inspection instruments)

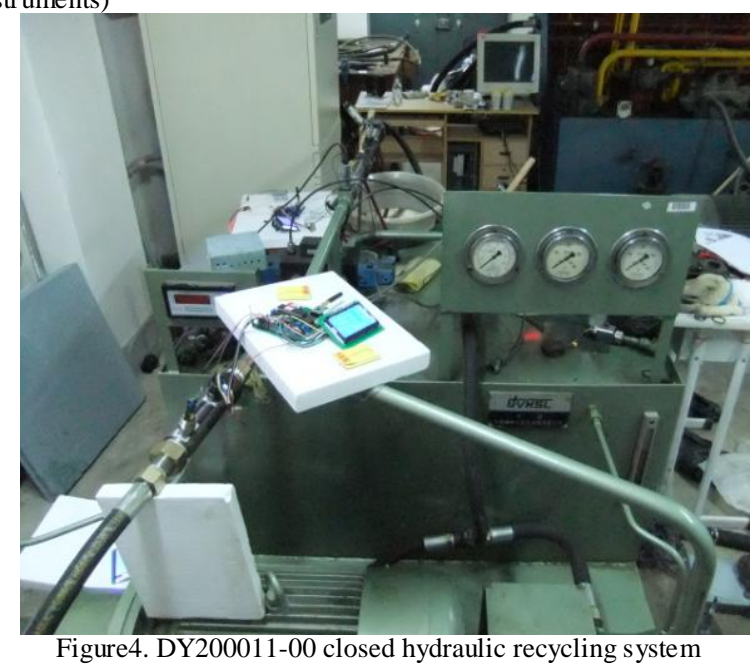

\section{B. Experiment data}

The power characteristic parameters acquired by hydraulic failure inspection system are shown in the Tab.III. And then, these power parameters are sent to condition data base where the work of grey correlation degree analysis is finished.

TABLE III. POWER PARAMETER OF NORMAL AND FAILURE

\begin{tabular}{|c|c|c|c|c|}
\hline \multicolumn{5}{|c|}{ STATES } \\
\hline $\begin{array}{l}\text { Working } \\
\text { condition }\end{array}$ & item & $\begin{array}{l}\text { No.1 } \\
\text { instrument }\end{array}$ & $\begin{array}{l}\text { No.2 } \\
\text { instrument }\end{array}$ & $\begin{array}{l}\text { No.3 } \\
\text { instrument }\end{array}$ \\
\hline \multirow[t]{6}{*}{$30 \mathrm{~Hz}$} & 1 & 0.487 & 0.281 & 0.042 \\
\hline & 2 & 0.466 & 0.276 & 0.047 \\
\hline & 3 & 0.459 & 0.283 & 0.045 \\
\hline & 4 & 0.467 & 0.278 & 0.044 \\
\hline & 5 & 0.454 & 0.289 & 0.043 \\
\hline & Ave. & 0.467 & 0.281 & 0.044 \\
\hline \multirow{6}{*}{$\begin{array}{l}\text { Backpressu } \\
\text { re valve } \\
\text { open }\end{array}$} & 1 & 0.275 & 0.163 & 0.030 \\
\hline & 2 & 0.285 & 0.158 & 0.026 \\
\hline & 3 & 0.289 & 0.158 & 0.031 \\
\hline & 4 & 0.282 & 0.162 & 0.033 \\
\hline & 5 & 0.293 & 0.157 & 0.032 \\
\hline & Ave. & 0.285 & 0.160 & 0.030 \\
\hline \multirow{6}{*}{$\begin{array}{l}\text { Main relief } \\
\text { valve open }\end{array}$} & 1 & 0.411 & 0.245 & 0.044 \\
\hline & 2 & 0.419 & 0.241 & 0.039 \\
\hline & 3 & 0.410 & 0.240 & 0.042 \\
\hline & 4 & 0.422 & 0.249 & 0.041 \\
\hline & 5 & 0.421 & 0.238 & 0.040 \\
\hline & Ave. & 0.417 & 0.243 & 0.041 \\
\hline \multirow{6}{*}{$\begin{array}{l}\text { Ball valve } \\
\text { close }\end{array}$} & 1 & 0.870 & 0.491 & 0.043 \\
\hline & 2 & 0.857 & 0.488 & 0.047 \\
\hline & 3 & 0.886 & 0.497 & 0.040 \\
\hline & 4 & 0.878 & 0.486 & 0.044 \\
\hline & 5 & 0.879 & 0.495 & 0.041 \\
\hline & Ave. & 0.874 & 0.491 & 0.043 \\
\hline
\end{tabular}




\section{Experiment results}

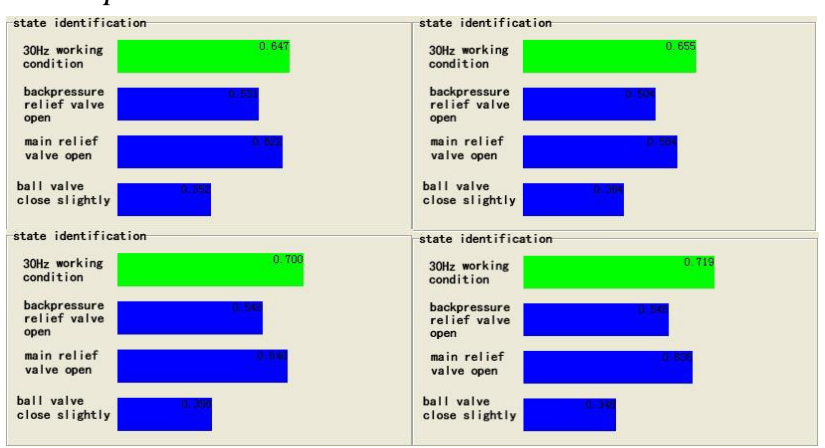

Figure5. state identification of $30 \mathrm{~Hz}$ operation

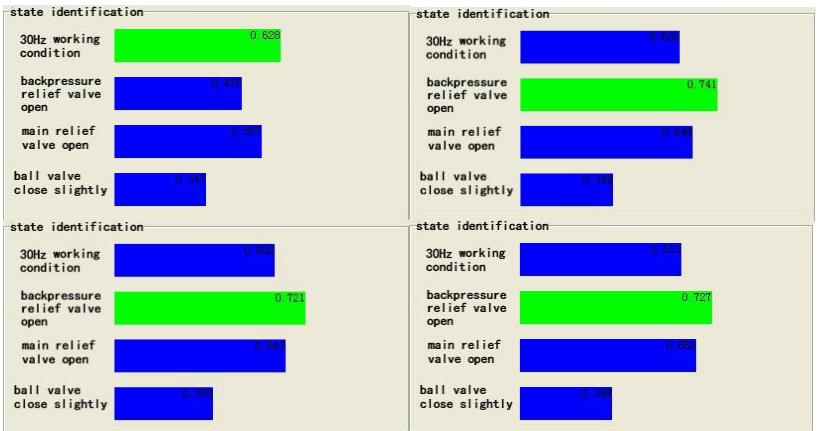

Figure6. state identification of opening backpressure

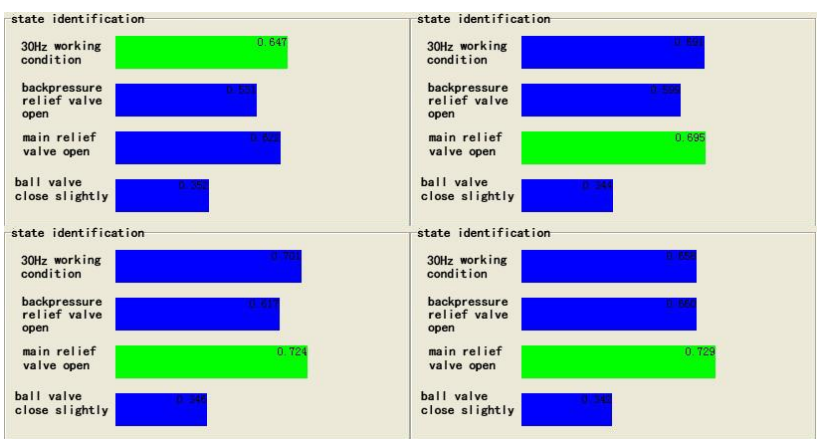

Figure7. state identification of opening main relief valve

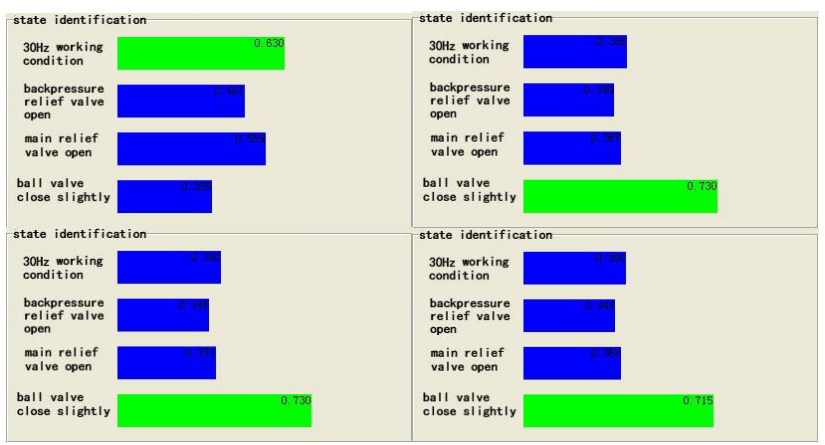

Figure 8. state identification of closing ball valve

In the interface of multi-instrument failure inspection, under the condition of normal state (the frequent of electronic motor is $30 \mathrm{~Hz}$ ), grey correlation degree calculation is done between the different states (four states) and operating parameter of system, the results indicate that the correlation degree between normal state (the frequent of electronic motor is $30 \mathrm{~Hz}$ ) and operating parameter of system is the largest, which certifying the correction of this state identification system. As is shown in Fig.5.

When opening the backpressure valve, the results of state identification were shown in Fig.6. The first picture shows the correlation degree under the condition of normal state (the frequent of electronic motor is $30 \mathrm{~Hz}$ ), the rest pictures show the correlation degree after opening the backpressure valve. Obviously, the correlation degree between operating parameters of system and backpressure valve opening state is the largest, which is consistent with the real condition.

When opening the main relief valve, the results of state identification were shown in Fig.7. We will find that it is difficult to identify the states of opening the main relief valve and normal state due to the similar correlation degree. The reason inducing this phenomenon is the little overflow of the relief valve because of clogging partly.

When closing the ball valve slightly, which means regulating the flow rate of hydraulic pump, the results of state identification were shown in Fig.8. the results indicate that the state identification is excellent.

\section{CONCLUSION}

The hydraulic power intelligent instrument designed in this paper can be applied in the hydraulic failure inspection system, which is verified by experiment. As a result, a newly hydraulic failure inspection method based on power acquiring is approved. During the performance test for the power sensor designed in this paper, the accuracy can not reach the excellent level, especially the linearity and the total uncertainty, but this has little influence to the designed hydraulic failure inspection system, which is verified by experiment. During the failure inspection experiment, the hydraulic power intelligent instrument can acquire power signal of inspection points continuously and real-timely. Besides, the operating condition of hydraulic system also can be identified accurately by the hydraulic power intelligent instrument.

\section{REFERENCES}

[1] ZHANG Hong-peng, GU Chang-zhi, ZHANG Yin-dong, MEI-tao, CHEN Hai-quan, SUN Yu-qing. Hydraulic power measurement device based MEMS reducer flow rate sensor: China, CN101349296A[P]. 2009-01-21.

2] ZHANG Hong-peng, YANG Hai-jun, ZHANG Yin-dong, LI Wenhua, YAN-xin. Newly flow rate measurement device using inside micro-differential pressure sensor: China, CN200510047936. 0[P] 2007-06-13.

[3] LIU-dong, Theoretical and Experimental Research on Power Intelligent Instrument in Ship Hydraulic System[D]. Dalian: Dalian Maritime University, 2011

[4] Nordic VLSI ASA. PRODUCT SPECIFICATION - Single chip 433/868/915 MHzTransceiver nRF905, January 2004.

[5] LIU Tong-fa, XIAO Zhi-gang, PENG Ji-wei. C programming model of C51chip and application engineering[M]. Beijing: Beihang University press, 2010

[6] ZHOU Li-gong MCU development limited cooperation in Guangzhou. Product data of P89V51RB2/RC2/RD2, 2004

[7] Hansheng limited cooperation. Introduction to LCD display module for HS12864-15series product. 2008

[8] WANG Dong-jie, interface technology and principle of MCU[M] Dalian: Dalian Maritime University Press, 2002

[9] HEADLAND Flo-tech. Hydraulic Diagnostic Products. Racine Federated Inc. ,2009-07 
[10] LIU-yu, LEI Yun-hong, WU Wang-yang. Design and diagnosis of the ship's portable hydraulic detecting equipment[J], Chinese Hydraulics and Pneumatics, 2011-7: 84-85

[11] CHEN Zi-jian, LEI Yun-hong, HE-chao,analysis on optimal sensor placement of water craft hydraulic equipment malfunction detection and diagnosis[J], Journal of Academy of Armored Force Engineering, Vol 22, Aug. 2008: 72-74

[12] LIU Hong-xing, LIN Jing, QU Liang-sheng, discussion on signal Averaging in Time Domain [J], Journal of Vibration Engineering, Vol10, Dec.1997, pp:447-451

[13] DENG Ju-long, foundamatal method for the gey system[M]. Wuhan: Huazhong University of Science and Technology Press, 1987

[14] XIANG Han, research on the hydraulic fault diagnosis expert system based on the dynamic monitoring[D], Xi'an: Chang'an University, 2013 